\title{
Sequential Spectrophotometric Method for the Simultaneous Determination of Amlodipine, Valsartan, and Hydrochlorothiazide in Coformulated Tablets
}

\author{
Hany W. Darwish, ${ }^{1,2}$ Said A. Hassan, ${ }^{1}$ Maissa Y. Salem, ${ }^{1}$ and Badr A. El-Zeany ${ }^{1}$ \\ ${ }^{1}$ Department of Analytical Chemistry, Faculty of Pharmacy, Cairo University, Kasr El-Aini Street, Cairo 11562, Egypt \\ ${ }^{2}$ Pharmaceutical Chemistry Department, College of Pharmacy, King Saud University, P.O. Box 2457, Riyadh 11451, Saudi Arabia \\ Correspondence should be addressed to Said A. Hassan; saidmonem_84@yahoo.com
}

Received 27 February 2013; Accepted 21 August 2013

Academic Editor: Karol Jackowski

Copyright ( $\odot 2013$ Hany W. Darwish et al. This is an open access article distributed under the Creative Commons Attribution License, which permits unrestricted use, distribution, and reproduction in any medium, provided the original work is properly cited.

\begin{abstract}
A new, simple and specific spectrophotometric method was developed and validated in accordance with ICH guidelines for the simultaneous estimation of Amlodipine (AML), Valsartan (VAL), and Hydrochlorothiazide (HCT) in their ternary mixture. In this method three techniques were used, namely, direct spectrophotometry, ratio subtraction, and isoabsorptive point. Amlodipine (AML) was first determined by direct spectrophotometry and then ratio subtraction was applied to remove the AML spectrum from the mixture spectrum. Hydrochlorothiazide (HCT) could then be determined directly without interference from Valsartan (VAL) which could be determined using the isoabsorptive point theory. The calibration curve is linear over the concentration ranges of 4-32, 4-44 and 6-20 $\mu \mathrm{g} / \mathrm{mL}$ for AML, VAL, and HCT, respectively. This method was tested by analyzing synthetic mixtures of the above drugs and was successfully applied to commercial pharmaceutical preparation of the drugs, where the standard deviation is $<2$ in the assay of raw materials and tablets. The method was validated according to the ICH guidelines and accuracy, precision, repeatability, and robustness were found to be within the acceptable limits.
\end{abstract}

\section{Introduction}

Many analytical methods have been introduced for the analysis of mixtures among which the molecular absorption spectroscopy was the most simple, fast, and applicable in laboratories. Molecular absorption spectroscopy has been extensively used for the determination of drugs in pharmaceutical preparations with a view to the development of analytical methods. The use of this technique for pharmaceutical analyses has the inherent constraint that most active drugs absorb in the UV region and exhibit strongly overlapped spectra that impede their simultaneous determination.

Direct spectrophotometry cannot resolve the drugs in their mixtures with impurities or other drugs, so several manipulations were performed to enable resolution of binary and ternary mixtures. Binary mixtures can be determined using different order derivatives [1], methods manipulating ratio spectra $[2,3]$ or dual wavelength [4-6], and isoabsorptive method [7]. For ternary mixtures, few spectrophotometric methods could resolve the overlap in their spectra, namely, Derivative Ratio Zero Crossing [8] and Double Divisor Ratio Spectra-Derivative Spectrophotometry [9] methods.

This paper describes the development and subsequent validation of a novel, simple, and rapid spectrophotometric method "Sequential Spectrophotometry" for simultaneous quantitation of ternary mixtures. The method was applied on a ternary mixture of AML, VAL, and HCT in bulk powder and pharmaceutical dosage forms. The linearity of response, accuracy, intermediate precision, and robustness of the described method for assay of AML, VAL, and HCT have been checked.

Amlodipine (AML), 2-[(2-aminoethoxy)methyl]-4-(2chlorophenyl)-1,4-dihydro-6-methyl-3,5-pyridine carboxylic acid 3-ethyl 5-methyl ester [10], (Figure 1), is a dihydropyridine derivative with calcium antagonist activity. It is used 
<smiles>CCOC(=O)C1=C(COCCN)NC(C)=C(C(=O)OC)C1c1ccccc1Cl</smiles>

(a)<smiles>CCCCC(=O)N(Cc1ccc(-c2ccccc2-c2nn[nH]n2)cc1)[C@@H](C(=O)O)C(C)C</smiles>

(b)<smiles>NS(=O)(=O)c1cc2c(cc1Cl)NCNS2(=O)=O</smiles>

(c)

FIgURE 1: Structural formulae for (a) Amlodipine, (b) Valsartan, and (c) Hydrochlorothiazide.

in the management of hypertension, chronic stable angina pectoris, and prinzmetal's variant angina [11].

Valsartan (VAL) (chemically described as N-[p-(o-1Htetrazol-5-ylphenyl)benzyl]-N-valeryl-L-valine [10] Figure 1), is a potent and specific competitive antagonist of the angiotensin-II $\mathrm{AT}_{1}$-receptor. It is used for treatment of hypertension, heart failure, and post-myocardial infarction [12].

Hydrochlorothiazide (HCT), 6-chloro-3,4-dihydro2H-1,2,4-benzothiadiazine-7-sulphonamide-1,1-dioxide [10] Figure 1, is a diuretic of the class of benzothiadiazines widely used in antihypertensive pharmaceutical formulations, alone or in combination with other drugs [13].

Literature survey revealed that Amlodipine besylate and Hydrochlorothiazide are official in the British Pharmacopoeia [14], Valsartan, Hydrochlorothiazide, and their mixture are official in the United States Pharmacopoeia [15]. There are reported methods for the determination of AML, VAL, or HCT in different dosage forms [2, 4, 16-19] and in their binary mixtures [20-22]. Few methods were reported for the simultaneous estimation of AML, VAL, and HCT in their ternary mixture [23-26] and only one spectrophotometric method was developed for the determination of this mixture [27]. In previous work, the authors developed derivative and chemometric methods for the analysis of the same mixture [28].

\section{Experimental}

\subsection{Samples}

\subsubsection{Pure Samples}

(a) Pure Amlodipine. It was kindly supplied by Al-Hekma pharmaceutical Company, Cairo, Egypt; its purity was certified to be $99.89 \pm 0.691$.

(b) Pure Valsartan. It was kindly supplied by Novartis pharmaceutical Company, Cairo, Egypt; its purity was certified to be $99.69 \pm 0.231$. (c) Pure Hydrochlorothiazide. It was kindly supplied by Al-Hekma pharmaceutical Company, Cairo, Egypt; its purity was certified to be $99.78 \pm 0.364$.

2.1.2. Market Samples. Three EXFORGE HCT tablet dosage forms, labeled to contain 5(AML)/160(VAL)/12.5(HCT) mg batch number 5002125, 5/160/25 mg batch number 5002141, and $10 / 320 / 25 \mathrm{mg}$ batch number 5002159 , manufactured by Novartis Pharmaceuticals Corporation, USA. They were procured from the USA. market.

\subsection{Reagents}

Methanol. It was purchased from El-NASR, Egypt.

2.3. Instruments. SHIMADZU dual beam UV-visible spectrophotometer (Kyoto/Japan), model UV-1650 PC connected to IBM compatible and an HP1020 laserjet printer were used. The bundled software, UV-Probe personal spectroscopy software version 2.21 (SHIMADZU) was used. The spectral band was $2 \mathrm{~nm}$ and scanning speed is $2800 \mathrm{~nm} / \mathrm{min}$ with $0.1 \mathrm{~nm}$ interval.

\subsection{Procedures}

\subsubsection{Standard Solutions}

(a) Standard stock solutions of AML, VAL, and HCT $1 \mathrm{mg} / \mathrm{mL}$ in methanol were used.

(b) Standard working solutions for AML and VAL $80 \mu \mathrm{g} / \mathrm{mL}$ and for HCT $62.5 \mu \mathrm{g} / \mathrm{mL}$ were prepared from stock solutions by appropriate dilutions with methanol.

2.4.2. Spectral Characteristics of $A M L, V A L$, and HCT. The zero order $\left(D_{0}\right)$ absorption spectrum of AML, VAL, and HCT $(20 \mu \mathrm{g} / \mathrm{mL}$ for each) solutions was recorded against methanol as a blank over the range of $200-400 \mathrm{~nm}$. 
The zero order $\left(D_{0}\right)$ absorption spectrum of $16 \mu \mathrm{g} / \mathrm{mL}$ VAL, $16 \mu \mathrm{g} / \mathrm{mL} \mathrm{HCT}$, and a binary mixture of VAL and HCT $(8 \mu \mathrm{g} / \mathrm{mL}$ for each) were recorded against methanol as a blank over the range of 200 to $400 \mathrm{~nm}$.

2.4.3. Construction of Calibration Curves. Aliquots equivalent to 40-320 $\mu \mathrm{g}$ AML, 40-440 $\mu \mathrm{g}$ VAL and 20-200 $\mu \mathrm{g}$ HCT were accurately transferred from their standard working solutions into three separate series of 10 - $\mathrm{mL}$ volumetric flasks then completed to volume with methanol. The spectra of the prepared standard solutions were scanned from $200-400 \mathrm{~nm}$ and stored in the computer.

For the determination of AML in presence of VAL and HCT, a calibration curve was constructed relating the absorbance of zero order spectra of AML at $359.4 \mathrm{~nm}$ to the corresponding concentration of AML and the regression equation was computed.

For the determination of HCT in presence of AML and VAL, a calibration curve was constructed relating the absorbance of zero order spectra of HCT at $316.4 \mathrm{~nm}$ to the corresponding concentration and the regression equation was computed.

For the determination of VAL in presence of AML and HCT, the isoabsorptive method was applied by measuring the absorbance of VAL and HCT at $256.8 \mathrm{~nm}\left(A_{\text {iso }}\right)$. Two calibration curves relating the absorbance to the corresponding drug concentrations were constructed, and the corresponding regression equations were computed.

2.4.4. Analysis of AML, VAL, and HCT in Laboratory Prepared Mixtures (Specificity). Aliquots of AML, VAL, and HCT were transferred from their standard working solutions into a series of $10 \mathrm{~mL}$ measuring flasks, completed to volume with methanol to prepare mixtures containing different ratios of AML, VAL, and HCT. The spectra of these mixtures were scanned from 200 to $400 \mathrm{~nm}$ and stored in the computer.

For the determination of AML in presence of VAL and $\mathrm{HCT}$, the same procedure under linearity was applied and the concentration of AML was calculated from the corresponding regression equation.

For the determination of HCT in the presence of AML and VAL, the stored mixture spectra were divided by the spectrum of normalized AML, and the constant was subtracted from the ratio spectra followed by multiplication of the obtained spectra by the divisor. The result of these steps is the spectra of VAL and HCT binary mixture. The absorbance values at $316.4 \mathrm{~nm}$ (where VAL shows no interference) were recorded and the concentration of HCT was calculated from the corresponding regression equation.

For the determination of VAL in presence of HCT, the absorbance at $\left(A_{\text {iso }}\right)$ in the binary mixture of VAL and HCT (after removal of AML) was measured, and then the total content of VAL and HCT was calculated from the corresponding regression equation. Subtraction of HCT concentration from the total concentration yields the actual concentration of VAL in the mixture.

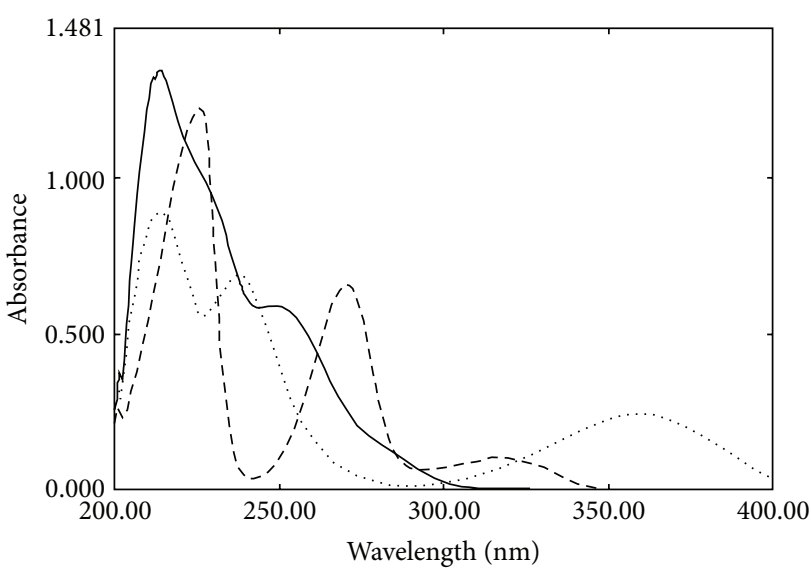

Figure 2: Zero order absorption spectra of $20 \mu \mathrm{g} / \mathrm{mL}$ AML $(\cdots)$, $20 \mu \mathrm{g} / \mathrm{mL}$ VAL (-), and $20 \mu \mathrm{g} / \mathrm{mL}$ HCT (- - ) using methanol as blank.

2.4.5. Analysis of AML, VAL, and HCT in Exforge HCT Tablets. Five tablets of each Exforge HCT formulation were accurately weighed and finely powdered. An amount of the powder equivalent to $8 \mathrm{mg}$ VAL was weighed and dissolved in methanol by shaking in ultrasonic bath for about 30 minutes. The solutions were filtered into separate $100 \mathrm{~mL}$ measuring flasks, and the volume was completed with methanol. Five $\mathrm{mL}$ was transferred into $10 \mathrm{~mL}$ measuring flasks, suitable aliquots of AML and HCT were transferred from their standard working solutions for spiking the solution to reach concentrations of linearity range, and then volume was completed with methanol. The spectra of these solutions were scanned from 200 to $400 \mathrm{~nm}$ and stored in the computer. The same procedure under laboratory prepared mixtures was applied and the concentrations of AML, VAL, and HCT were calculated from the corresponding regression equations.

\section{Results and Discussion}

Sequential spectrophotometry depends on the presence of extended spectrum of one of the three drugs, so ratio subtraction technique can be used to remove this extended spectrum producing spectrum of the other two drugs. The second step depends on determination of the other two drugs by any spectrophotometric method that can resolve binary mixtures $[6,7,29-33]$.

In this work, after direct determination of AML, we applied ratio subtraction to remove its extended spectrum producing a spectrum of HCT and VAL, where HCT was determined directly. Then the total concentration of HCT and VAL was calculated at their isoabsorptive point and VAL concentration was calculated by subtraction.

3.1. Determination of AML. The absorption spectra of the three compounds, AML, VAL, and HCT, show highly overlapped spectra in the region 200-300 nm (Figure 2). AML can be determined at $359.4 \mathrm{~nm}$ directly where VAL and HCT show no absorbance. 


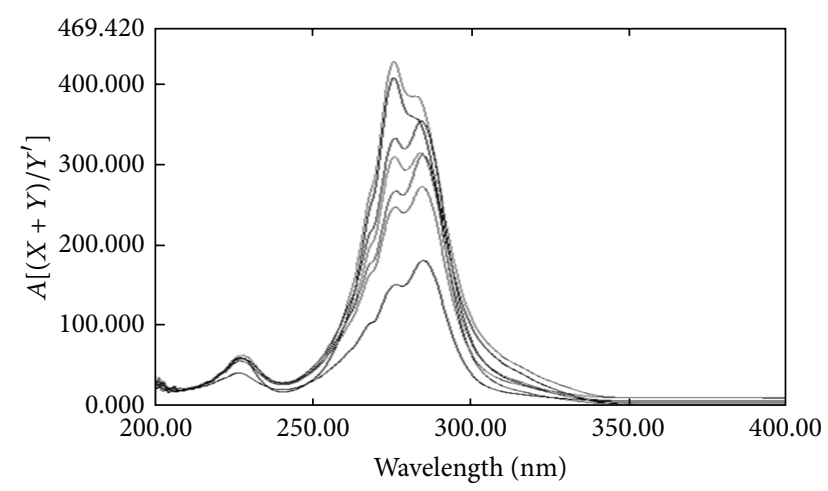

FIGURE 3: Ratio spectra of laboratory prepared mixtures of AML $(Y)$ and VAL $+\operatorname{HCT}(X)$ using normalized AML $\left(Y^{\prime}\right)$ as a divisor and methanol as a blank.

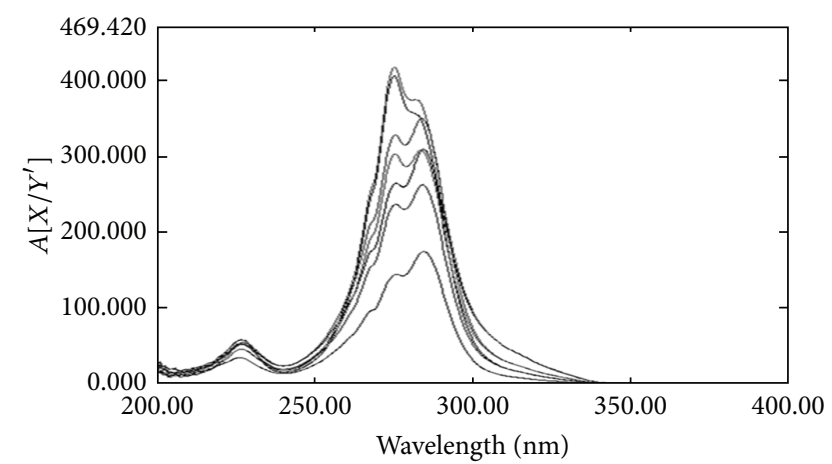

FIGURE 4: Ratio spectra of laboratory prepared mixtures of AML $(Y)$ and VAL + HCT $(X)$ using normalized AML $\left(Y^{\prime}\right)$ as a divisor and methanol as a blank after subtraction of the constant.

A linear correlation was obtained between the absorbance and the corresponding concentration of AML at $359.4 \mathrm{~nm}$. The regression equation was calculated as follows:

$$
P_{\mathrm{AML}}=0.0162 \mathrm{C}+0.0010, \quad r=0.9998,
$$

where $C$ is the concentration of AML in $\mu \mathrm{g} / \mathrm{mL}, P$ is the peak amplitude of the zero order spectrum of AML at $359.4 \mathrm{~nm}$, and $r$ is the correlation coefficient.

3.2. Determination of HCT. For the determination of both HCT and VAL, ratio subtraction technique was applied for removing AML spectrum.

The method depends on that when a mixture of VAL + $\operatorname{HCT}(X)$ and AML $(Y)$ where the spectrum of $(Y)$ is more extended (Figure 2), the determination of $(X)$ could be done by scanning the zero order absorption spectra of the laboratory prepared mixtures (AML and VAL + HCT), dividing them by carefully chosen concentration of standard AML $\left(Y^{\prime}=\right.$ divisor $)$ producing a new ratio spectra that represent $\left(X / Y^{\prime}\right)+$ constant as shown in Figure 3, then subtraction of the absorbance values of these constants $\left(Y / Y^{\prime}\right)$ in plateau as shown in Figure 4, followed by multiplication of the obtained spectra by the divisor $\left(Y^{\prime}\right)$. Finally, the original spectra of $(X)$ could be obtained (Figure 5), which were used for direct

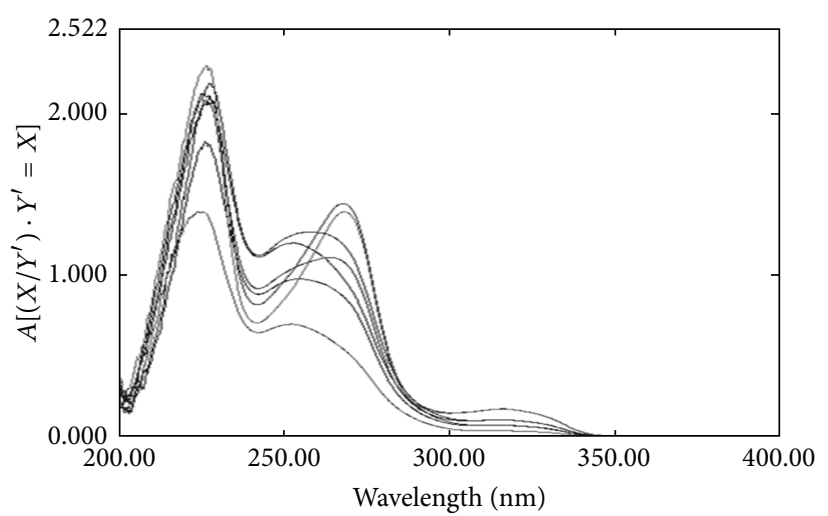

FIgURE 5: The zero order absorption spectra of VAL and HCT mixture obtained by the proposed ratio subtraction method for the analysis of laboratory prepared mixtures after multiplication by the divisor $\left(Y^{\prime}\right)$.

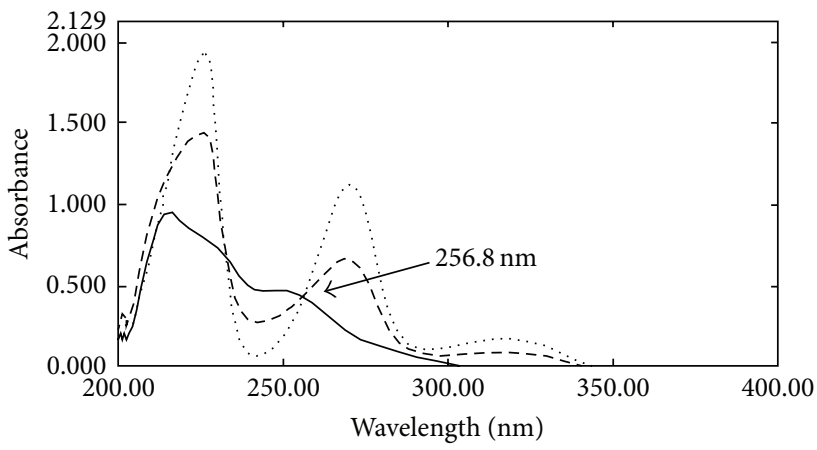

Figure 6: Zero order absorption spectra of $16 \mu \mathrm{g} / \mathrm{mL}$ VAL (-), $16 \mu \mathrm{g} / \mathrm{mL}$ HCT $(\cdots)$, and a mixture of $8 \mu \mathrm{g} / \mathrm{mL}$ VAL with $8 \mu \mathrm{g} /$ $\mathrm{mL} \mathrm{HCT} \mathrm{(---)} \mathrm{showing} \mathrm{isoabsorptive} \mathrm{point} \mathrm{at} 256.8 \mathrm{~nm}$ using methanol as blank.

TABLE 1: Determination of AML, VAL, and HCT in laboratory prepared mixtures by the proposed method.

\begin{tabular}{|c|c|c|c|c|c|}
\hline \multicolumn{3}{|c|}{ Concentration $(\mu \mathrm{g} / \mathrm{mL})$} & \multicolumn{3}{|c|}{ Proposed method recovery $\%$} \\
\hline AML & VAL & $\mathrm{HCT}$ & AML & VAL & HCT \\
\hline $4^{\mathrm{b}}$ & 40 & 6.25 & 101.01 & 101.38 & 97.78 \\
\hline 12 & 40 & 6.25 & 100.91 & 98.20 & 100.74 \\
\hline 20 & 40 & 6.25 & 99.53 & 100.04 & 100.74 \\
\hline 12 & 20 & 6.25 & 101.37 & 100.16 & 99.26 \\
\hline 12 & 4 & 6.25 & 101.55 & 97.34 & 100.74 \\
\hline 12 & 20 & 12.5 & 101.22 & 100.12 & 101.48 \\
\hline 4 & 4 & 12.5 & 98.26 & 99.82 & 100.74 \\
\hline \multicolumn{3}{|c|}{ Mean } & 100.55 & 99.58 & 100.21 \\
\hline \multicolumn{3}{|c|}{ SD } & 1.208 & 1.357 & 1.262 \\
\hline \multicolumn{3}{|c|}{ RSD\% } & 1.201 & 1.363 & 1.260 \\
\hline
\end{tabular}

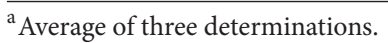

${ }^{\mathrm{b}}$ The ratio of dosage form.

determination of HCT at $316.4 \mathrm{~nm}$, where VAL shows no absorbance (Figure 2), and calculation of the concentration from the corresponding regression equation was done. 
TABLE 2: Determination of AML, VAL, and HCT in Exforge HCT tablets by the proposed method and the reported HPLC method [23] and application of standard addition technique.

\begin{tabular}{|c|c|c|c|c|c|c|c|}
\hline \multirow{2}{*}{ Product } & \multirow{2}{*}{ Drug } & \multirow{2}{*}{ Proposed method } & \multirow{2}{*}{ Reported method ${ }^{\mathrm{a}}$} & \multicolumn{4}{|c|}{ Standard addition } \\
\hline & & & & Taken $(\mu \mathrm{g} / \mathrm{mL})$ & Added $(\mu \mathrm{g} / \mathrm{mL})$ & Found $(\mu \mathrm{g} / \mathrm{mL})$ & Recovery $\%^{\mathrm{b}}$ \\
\hline \multirow{12}{*}{ Exforge HCT 5/160/12.5 } & \multirow{4}{*}{ AML } & \multirow{4}{*}{$99.91 \pm 1.069$} & \multirow{4}{*}{$100.40 \pm 0.636$} & \multirow{3}{*}{6} & 4 & 3.994 & 99.85 \\
\hline & & & & & 6 & 6.074 & 101.23 \\
\hline & & & & & 8 & 7.884 & 98.55 \\
\hline & & & & \multirow{4}{*}{16} & & Mean \pm RSD & $99.88 \pm 1.344$ \\
\hline & \multirow{3}{*}{$5 \mathrm{VAL}$} & \multirow{3}{*}{$99.50 \pm 0.951$} & \multirow{3}{*}{$100.13 \pm 0.884$} & & 12 & 12.259 & 102.16 \\
\hline & & & & & 16 & 16.14 & 100.88 \\
\hline & & & & & 20 & 20.175 & 100.88 \\
\hline & \multirow{5}{*}{ HCT } & \multirow{5}{*}{$99.83 \pm 1.282$} & \multirow{5}{*}{$100.13 \pm 0.729$} & \multirow{5}{*}{9.375} & & Mean \pm RSD & $101.30 \pm 0.730$ \\
\hline & & & & & 6.25 & 6.329 & 101.27 \\
\hline & & & & & 9.375 & 9.319 & 99.4 \\
\hline & & & & & 12.5 & 12.645 & 101.16 \\
\hline & & & & & & Mean \pm RSD & $100.61 \pm 1.041$ \\
\hline \multirow{12}{*}{ Exforge HCT 5/160/25 } & \multirow{4}{*}{ AML } & \multirow{4}{*}{$101.01 \pm 1.650$} & \multirow{4}{*}{$99.85 \pm 0.970$} & \multirow{4}{*}{6} & 4 & 3.985 & 99.61 \\
\hline & & & & & 6 & 6.121 & 102.02 \\
\hline & & & & & 8 & 7.987 & 99.84 \\
\hline & & & & & & Mean \pm RSD & $100.49 \pm 1.326$ \\
\hline & \multirow{3}{*}{ VAL } & \multirow{3}{*}{$100.27 \pm 1.403$} & \multirow{3}{*}{$100.00 \pm 0.859$} & & 12 & 11.935 & 99.46 \\
\hline & & & & 16 & 16 & 16.379 & 102.37 \\
\hline & & & & & 20 & 20.171 & 100.86 \\
\hline & & & & & & Mean \pm RSD & $100.89 \pm 1.440$ \\
\hline & & & & & 6.25 & 6.334 & 101.34 \\
\hline & $\mathrm{HCT}$ & $99.26 \pm 1.493$ & $99.71 \pm 0.693$ & 9.375 & 9.375 & 9.533 & 101.68 \\
\hline & & & & & 12.5 & 12.524 & 100.19 \\
\hline & & & & & & Mean \pm RSD & $101.07 \pm 0.774$ \\
\hline & & & & & 4 & 4.01 & 100.24 \\
\hline & AML & $100.20 \pm 1.173$ & $100.37 \pm 0.712$ & 6 & 6 & 5.934 & 98.91 \\
\hline & & & & & 8 & 8.038 & 100.47 \\
\hline & & & & & & Mean \pm RSD & $99.87 \pm 0.846$ \\
\hline & & & & & 12 & 12.101 & 100.84 \\
\hline Fyforge HCT $10 / 320 / 25$ & VAL & $99.93 \pm 0.897$ & $100.55 \pm 0.595$ & 16 & 16 & 15.949 & 99.68 \\
\hline 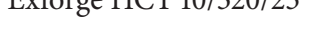 & & & & & 20 & 19.797 & 98.99 \\
\hline & & & & & & Mean \pm RSD & $99.84 \pm 0.939$ \\
\hline & & & & & 6.25 & 6.344 & 101.5 \\
\hline & $\mathrm{HCT}$ & $99.75 \pm 1.045$ & $100.23 \pm 0.825$ & 9.375 & 9.375 & 9.27 & 98.88 \\
\hline & & & & & 12.5 & 12.761 & 102.09 \\
\hline & & & & & & Mean \pm RSD & $100.82 \pm 1.695$ \\
\hline
\end{tabular}

${ }^{a}$ HPLC method using Luna $\mathrm{C}_{18}$ column, a mobile phase consisting of methanol-phosphate buffer $(30 \mathrm{mM}, \mathrm{pH} 5.5)(62: 38$ by volume) at a flow rate of $1 \mathrm{~mL} / \mathrm{min}$, and UV detection at $234 \mathrm{~nm}$.

${ }^{\mathrm{b}}$ Average of three determinations.

The constant can be determined directly from the curve $(X+Y) / Y^{\prime}$ by the straight line which is parallel to the wavelength axis in the region where $(Y)$ is extended.

The linearity was checked between absorbance at the selected wavelength $316.4 \mathrm{~nm}$ and the corresponding concentration of HCT. A linear correlation was obtained and the regression equation was found to be

$$
P_{\mathrm{HCT}}=0.0108 \mathrm{C}+0.0030, \quad r=0.9998,
$$

where $C$ is the concentration of $\mathrm{HCT}$ in $\mu \mathrm{g} / \mathrm{mL}, P$ is the peak amplitude of the zero order spectrum of HCT at $316.4 \mathrm{~nm}$, and $r$ is the correlation coefficient.

3.3. Determination of VAL. The absorbance spectra of $16 \mu \mathrm{g} / \mathrm{mL}$ VAL, $16 \mu \mathrm{g} / \mathrm{mL}$ of HCT, and a mixture containing equal concentrations of VAL and HCT $(8 \mu \mathrm{g} / \mathrm{mL}$ of each) showed isoabsorptive point at $256.8 \mathrm{~nm}$ (Figure 6). 
TABLE 3: Statistical comparison for the results obtained by the proposed spectrophotometric method and the reported method [23] for the analysis of AML, VAL, and HCT in Exforge HCT tablets.

\begin{tabular}{|c|c|c|c|c|c|c|}
\hline \multirow{2}{*}{ Value } & \multicolumn{3}{|c|}{ Proposed method } & \multicolumn{3}{|c|}{ Reported method ${ }^{\mathrm{a}}$} \\
\hline & AML & VAL & HCT & AML & VAL & HCT \\
\hline Mean & 100.37 & 99.90 & 99.61 & 100.21 & 100.23 & 100.03 \\
\hline SD & 1.252 & 1.015 & 1.141 & 0.733 & 0.730 & 0.693 \\
\hline RSD \% & 1.247 & 1.016 & 1.145 & 0.731 & 0.728 & 0.693 \\
\hline$n$ & 9 & 9 & 9 & 9 & 9 & 9 \\
\hline Variance & 1.567 & 1.030 & 1.302 & 0.537 & 0.533 & 0.480 \\
\hline Student's $t$ test ${ }^{\mathrm{b}}$ & $0.343(2.16)$ & $0.788(2.131)$ & $0.927(2.16)$ & - & - & - \\
\hline$F$ value $^{\mathrm{b}}$ & $2.921(3.438)$ & $1.933(3.438)$ & $2.710(3.438)$ & - & - & - \\
\hline
\end{tabular}

${ }^{a}$ HPLC method using Luna $\mathrm{C}_{18}$ column, a mobile phase consisting of methanol-phosphate buffer ( $\left.30 \mathrm{mM}, \mathrm{pH} 5.5\right)(62: 38$ by volume) at a flow rate of $1 \mathrm{~mL} / \mathrm{min}$, and UV detection at $234 \mathrm{~nm}$.

${ }^{\mathrm{b}}$ The values in the parenthesis are the corresponding theoretical values of $t$ and $F$ at $P=0.05$.

TABLE 4: Assay validation sheet of the proposed spectrophotometric method for the simultaneous determination of AML, VAL, and HCT.

\begin{tabular}{lccc}
\hline Parameter & \multicolumn{2}{c}{ Proposed method } & HCT \\
\hline Accuracy (mean \pm RSD) & AML & $99.66 \pm 0.956$ & $100.24 \pm 0.679$ \\
Precision & $99.93 \pm 1.188$ & & 0.651 \\
$\quad$ Repeatability $^{\mathrm{a}}$ & 0.535 & 1.225 & 0.867 \\
$\quad$ Intermediate precision $^{\mathrm{b}}$ & 1.061 & 0.633 & 0.002 \\
Robustness $^{c}$ & 0.704 & & 0.0108 \\
Linearity $^{\text {Slope }}$ & & 0.0258 & 0.0030 \\
$\quad$ Intercept & 0.0162 & 0.0051 & 0.9998 \\
$\quad$ Correlation coefficient $(r)$ & 0.0010 & 0.9998 & $6-20$ \\
$\quad$ Range $(\mu \mathrm{g} / \mathrm{mL})$ & 0.9998 & $4-44$ & \\
\hline
\end{tabular}

a The intraday $(n=3)$ average of three concentrations $(12,16,20 \mu \mathrm{g} / \mathrm{mL})$ for AML, VAL, and HCT repeated three times within the day.

${ }^{\mathrm{b}}$ The interday $(n=3)$ average of three concentrations $(12,16,20 \mu \mathrm{g} / \mathrm{mL})$ for AML, VAL, and HCT repeated three times in three days.

${ }^{c}$ Robustness $(n=3)$ average of three concentrations $(12,16,20 \mu \mathrm{g} / \mathrm{mL})$ for AML, VAL, and HCT analyzed using 75 and $70 \%$ methanol.

By measuring the absorbance value at the chosen isoabsorptive point in the zero order absorption spectrum obtained from ratio subtraction method, the total content of VAL and HCT in the mixture can be calculated, while the content of HCT alone can be calculated using the zero order absorption spectrum obtained from ratio subtraction method without any interference from VAL. Thus the content of VAL can be calculated by subtraction.

By applying the isoabsorptive point, linear correlation was obtained between the absorbance values at $256.8 \mathrm{~nm}$ $\left(A_{\text {iso }}\right)$ and corresponding concentrations of VAL and HCT. The regression equations were computed as follows:

$$
\begin{array}{ll}
P_{\mathrm{VAL}}=0.0258 C+0.0051, & r=0.9998, \\
P_{\mathrm{HCT}}=0.0254 C-0.0031, & r=0.9993,
\end{array}
$$

where $C$ is the concentration of VAL and HCT in $\mu \mathrm{g} / \mathrm{mL}, P$ is the peak amplitude of the zero order spectrum of VAL and $\mathrm{HCT}$ at $256.8 \mathrm{~nm}$, and $r$ is the correlation coefficient.

The proposed method was found to be valid in the range of $4-32 \mu \mathrm{g} / \mathrm{mL}, 4-44 \mu \mathrm{g} / \mathrm{mL}$, and $6-20 \mu \mathrm{g} / \mathrm{mL}$ for AML, VAL and HCT, respectively, as shown by the small intercept and correlation coefficient approaching unity in the regression equations.

The specificity of the proposed method was assessed by the analysis of laboratory prepared mixtures containing different ratios of the drugs, where satisfactory results were obtained over the calibration range as shown in Table 1.

The proposed method was also applied for the determination of AML, VAL, and HCT in Exforge HCT tablets and the validity of the proposed method was further assessed by applying the standard addition technique as presented in Table 2.

Results obtained by the proposed method for the determination of the drugs in Exforge HCT tablets were statistically compared [34] to those obtained by the reported HPLC method [23]; no significant differences between the results were obtained as presented in Table 3. A validation sheet according to ICH guidelines was also presented in Table 4.

The method shows simplicity over our previous work on the same mixture [28], where the determination of the three drugs needs more steps of division and derivatization or difficult calculations as in chemometrics. Also, the method is preferred over chromatographic methods as no expensive solvents or sophisticated instruments are required. 


\section{Conclusion}

From the previous discussion, it could be concluded that the new sequential spectrophotometry is simple, accurate, and specific and can be used for quantitation of ternary mixtures. The method was successfully applied for determination of a ternary mixture of AML, VAL, and HCT. The method is more rapid than chromatographic methods and does not need sample preparation or sophisticated techniques and instruments. It is also sensitive and selective and can be used for routine analysis of AML, VAL, and HCT in their pure powder and dosage forms.

\section{Disclosure}

The authors of the paper are academic staff in Cairo University and do not have a direct financial relationship with the commercial identities mentioned in the paper.

\section{References}

[1] N. Erk, "Spectrophotometric analysis of valsartan and hydrochlorothiazide," Analytical Letters, vol. 35, no. 2, pp. 283-302, 2002.

[2] H. W. Darwish, S. A. Hassan, M. Y. Salem, and B. A. El-Zeiny, "Three different spectrophotometric methods manipulating ratio spectra for determination of binary mixture of amlodipine and atorvastatin," Spectrochimica Acta A, vol. 83, no. 1, pp. 140148, 2011.

[3] E. S. Elzanfaly, A. S. Saad, and A. E. B. Abd-Elaleem, "Simultaneous determination of retinoic acid and hydroquinone in skin ointment using spectrophotometric technique (ratio difference method)," Saudi Pharmaceutical Journal, vol. 20, no. 3, pp. 249253, 2012.

[4] H. W. Darwish, S. A. Hassan, M. Y. Salem, and B. A. ElZeany, "Three different methods for determination of binary mixture of amlodipine and atorvastatin using dual wavelength spectrophotometry," Spectrochimica Acta A, vol. 104, pp. 70-76, 2013.

[5] H. W. Darwish, S. A. Hassan, M. Y. Salem, and B. A. El-Zeany, "Development and validation of h-point standard addition method applied for the analysis of binary mixture of amlodipine and atorvastatin," International Journal of Pharma \& Bio Sciences, vol. 4, no. 2, pp. 230-243, 2013.

[6] S. Shibata, "Dual-wavelength spectrophotometry," Angewandte Chemie, vol. 15, no. 11, pp. 673-679, 1976.

[7] S. V. Erram and H. P. Tipnis, "Simple spectrometric analysis of acebutolol hydrochloride and atenolol in combined pharmaceutical dosages with hydrochlorothiazide," Indian Drugs, vol. 30, no. 9, pp. 462-467, 1993.

[8] J. J. B. Nevado, C. G. Cabanillas, and F. Salinas, "Spectrophotometric resolution of ternary mixtures of salicylaldehyde, 3-hydroxybenzaldehyde and 4-hydroxybenzaldehyde by the derivative ratio spectrum-zero crossing method," Talanta, vol. 39, no. 5, pp. 547-553, 1992.

[9] E. Dinc and F. Onur, "Application of a new spectrophotometric method for the analysis of a ternary mixture containing metamizol, paracetamol and caffeine in tablets," Analytica Chimica Acta, vol. 359, no. 1-2, pp. 93-106, 1998.

[10] A. C. Moffat, M. D. Osselton, and B. Widdop, Clarke's Analysis of Drugs and Poisons, Pharmaceutical Press, London, UK, 2004.
[11] G. K. McEvoy, American Hospital Formulary Service, American Society of Health-System Pharmacists, Bethesda, Md, USA, 2001.

[12] R. Dina and M. Jafari, "Angiotensin II-receptor antagonistsan overview," American Journal of Health-System Pharmacy, vol. 57, no. 13, pp. 1231-1241, 2000.

[13] L. J. Brunton and K. L. Parker, Goodman \& Gilman's the Pharmacological Basis of Therapeutics, McGraw-Hill, New York, NY, USA, 2006.

[14] British Pharmacopoeia, Medicines and Healthcare Products Regulatory Agency (MHRA), London, UK, 2007.

[15] United States Pharmacopeia, United States Pharmacopeial Convention, Rockville, Md, USA, 2007.

[16] D. G. T. Parambi, M. Mathew, and V. Ganesan, "A validated stability indicating HPLC method for the determination of valsartan in tablet dosage forms," Journal of Applied Pharmaceutical Science, vol. 1, no. 4, pp. 97-99, 2011.

[17] S. K. Acharjya, M. M. Annapurna, and S. Koya, "Liquid chromatographic method for simultaneous estimation of atorvastatin calcium and amlodipine besylate in pharmaceutical dosage forms," International Journal of Pharma \& Bio Sciences, vol. 1, no. 4, pp. 161-170, 2010.

[18] A. Sharma, B. Patel, and R. Patel, "Simultaneous estimation of nebivolol hydrochloride and s-amlodipine besylate by high performance thin layer chromatography," International Journal of Pharma \& Bio Sciences, vol. 1, no. 4, pp. 339-347, 2010.

[19] N. Devanaboyina, T. Satyanarayana, and B. G. Rao, "Simultaneous determination of olmesartan and hydrochlorothiazide in combined pharmaceutical dosage form by Rp-Hplc method," International Journal of Pharma \& Bio Sciences, vol. 3, no. 2, pp. 107-115, 2012.

[20] N. K. Ramadan, H. M. Mohamed, and A. A. Moustafa, "Rapid and highly sensitive HPLC and TLC methods for quantitation of amlodipine besilate and valsartan in bulk powder and in pharmaceutical dosage forms and in human plasma," Analytical Letters, vol. 43, no. 4, pp. 570-581, 2010.

[21] G. Patel, S. Patel, D. Prajapiti, and R. Mehta, "RP-HPLC method for simultaneous estimation of amlodipine besylate and hydrochlorothiazide in combined dosage forms," Stamford Journal of Pharmaceutical Sciences, vol. 3, no. 1, pp. 49-53, 2011.

[22] D. Tian, X. Tian, T. Tian, Z. Wang, and F. Mo, "Simultaneous determination of valsartan and hydrochlorothiazide in tablets by RP-HPLC," Indian Journal of Pharmaceutical Sciences, vol. 70, no. 3, pp. 372-374, 2008.

[23] S. E. Vignaduzzo, P. M. Castellano, and T. S. Kaufman, "Development and validation of an HPLC method for the simultaneous determination of amlodipine, hydrochlorothiazide, and Valsartan in tablets of their novel triple combination and binary pharmaceutical associations," Journal of Liquid Chromatography and Related Technologies, vol. 34, no. 19, pp. 2383-2395, 2011.

[24] S. J. Varghese and T. K. R. Quantitative, "Simultaneous determination of amlodipine, valsartan, and hydrochlorothiazide in "exforge HCT" tablets using high-performance liquid chromatograhy and high- performance thinlayer chromatography," Journal of Liquid Chromatography \& Related Technologies, vol. 34, no. 12, pp. 981-994, 2011.

[25] Y. Reddy, M. Arif, M. Younus, and T. Reddy, "RP-HPLCMethod development and validation forsimultaneous estimation of amlodipine besylate,valsartan and hydrochlorothiazide in tablet dosageform," Journal of Pharmacy Research, vol. 3, no. 11, pp. 2647-2650, 2010. 
[26] H. W. Darwish, S. A. Hassan, M. Y. Salem, and B. A. ElZeany, "Rapid and sensitive TLC and HPLC with on-line wavelength switching methods for simultaneous quantitation of amlodipine, valsartan and hydrochlorothiazide in pharmaceutical dosage forms," International Journal of Pharma \& Bio Sciences, vol. 4, no. 1, pp. 345-356, 2013.

[27] K. Ananda and M. Jayamariappan, "Absorption correctionmethod for the simultaneous estimation of amlodipinebesylate, valsartan and hydrochlorothiazide in bulk and incombined tablet dosage form," International Journal of Pharmacy \& Pharmaceutical Sciences, vol. 3, no. 1, pp. 23-27, 2011.

[28] H. W. Darwish, S. A. Hassan, M. Y. Salem, and B. A. ElZeany, "Comparative study between derivative spectrophotometry and multivariate calibration as analytical tools applied for the simultaneous quantitation of amlodipine, valsartan and hydrochlorothiazide," Spectrochimica Acta A, vol. 113, pp. 215223, 2013.

[29] F. Salinas, J. J. B. Nevado, and A. E. Mansilla, "A new spectrophotometric method for quantitative multicomponent analysis resolution of mixtures of salicylic and salicyluric acids," Talanta, vol. 37, no. 3, pp. 347-351, 1990.

[30] M. G. El-Bardicy, H. M. Lotfy, M. A. El-Sayed, and M. F. ElTarras, "Smart stability-indicating spectrophotometric methods for determination of binary mixtures without prior separation," Journal of AOAC International, vol. 91, no. 2, pp. 299-310, 2008.

[31] P. Lopez-de-Alba, L. López-Martínez, K. Wrobel-Kaczmarczyk, K. Wrobel-Zasada, and J. Amador-Hernández, "The resolution of dye binary mixtures by bivariate calibration using spectrophotometric data," Analytical Letters, vol. 29, no. 3, pp. 487503, 1996.

[32] N. Erk, "Simultaneous determination of fosinopril and hydrochlorothiazide in pharmaceutical formulations by spectrophotometric methods," Journal of Pharmaceutical and Biomedical Analysis, vol. 27, no. 6, pp. 901-912, 2002.

[33] E. S. Elzanfaly, A. S. Saad, and A. E. Abd Elaleem, "A smart simple spectrophotometric method for simultaneous determination of binary mixtures," Journal of Pharmaceutical Analysis, vol. 2, no. 5, pp. 382-385, 2012.

[34] J. P. Romano and E. L. Lehmann, Testing Statistical Hypotheses, Springer, New York, NY, USA, 3rd edition, 2005. 

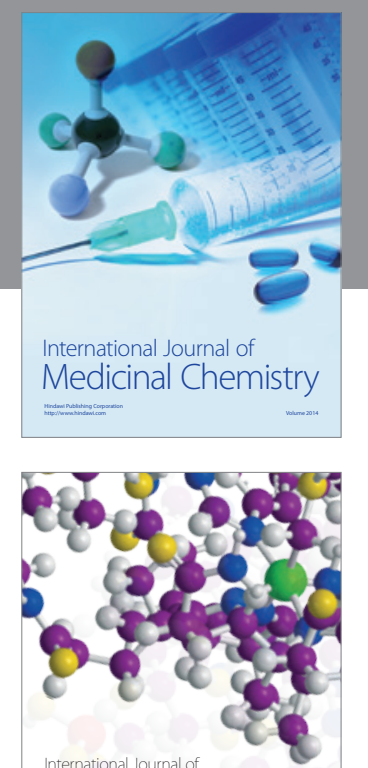

\section{Carbohydrate} Chemistry

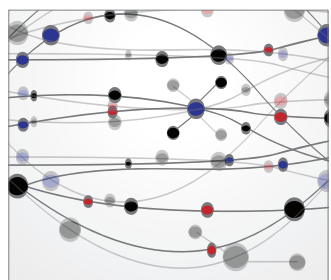

The Scientific World Journal
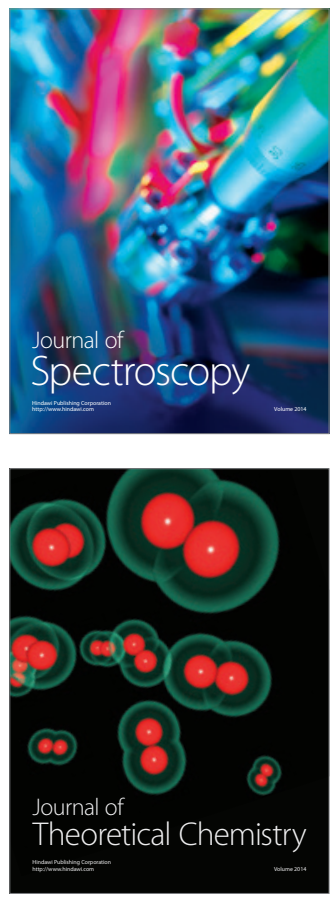
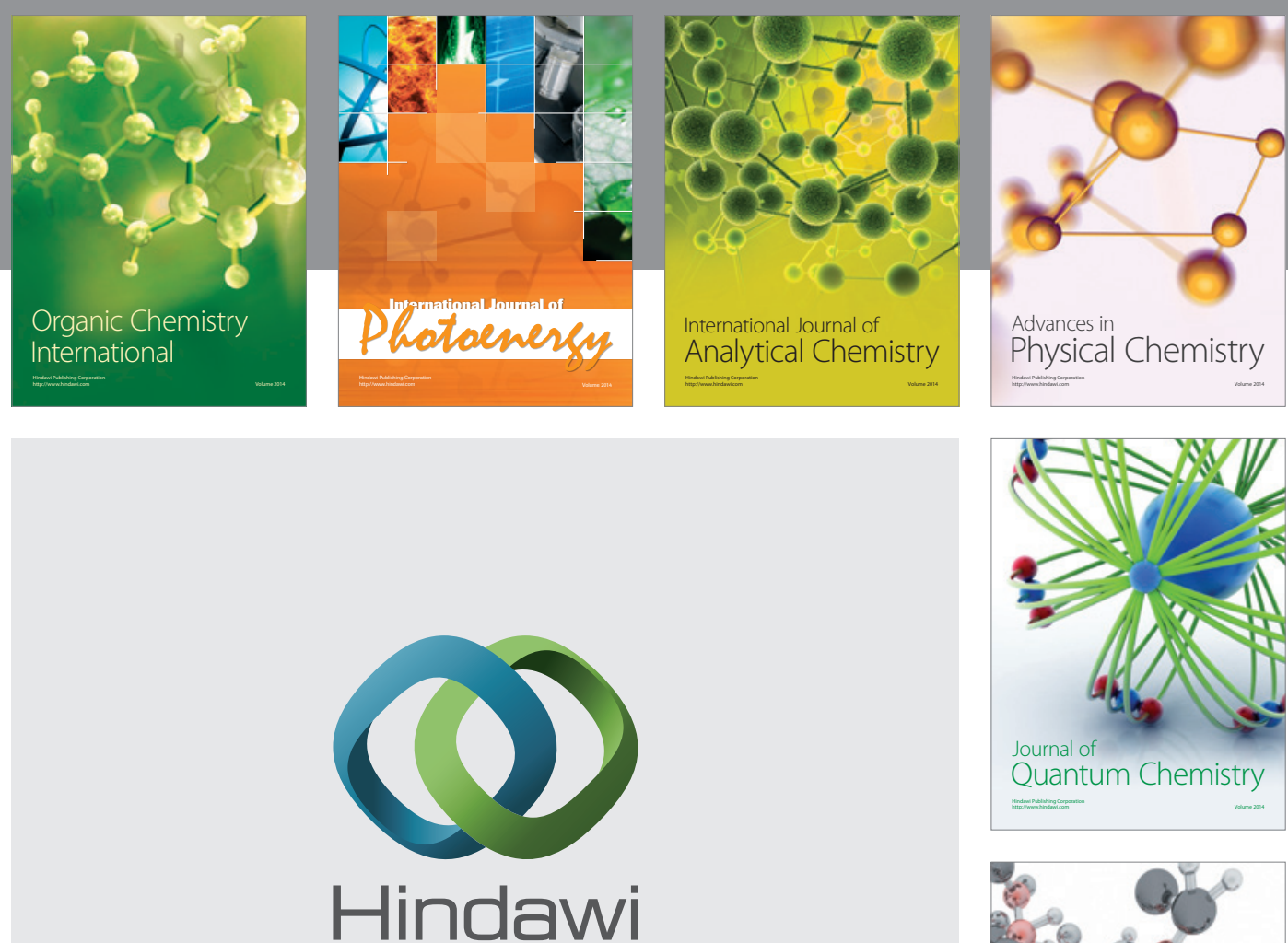

Submit your manuscripts at

http://www.hindawi.com

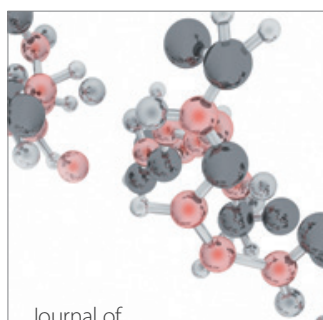

Analytical Methods

in Chemistry

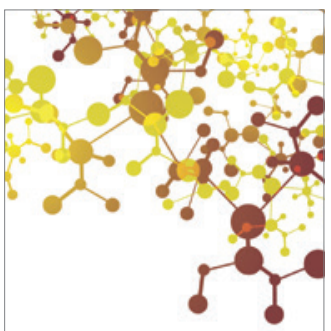

Journal of

Applied Chemistry

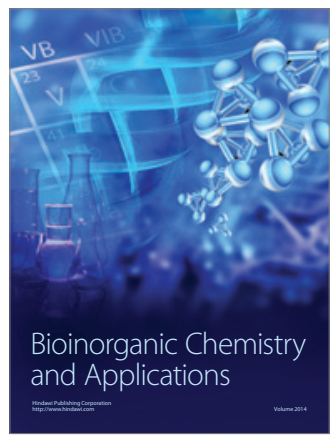

Inorganic Chemistry
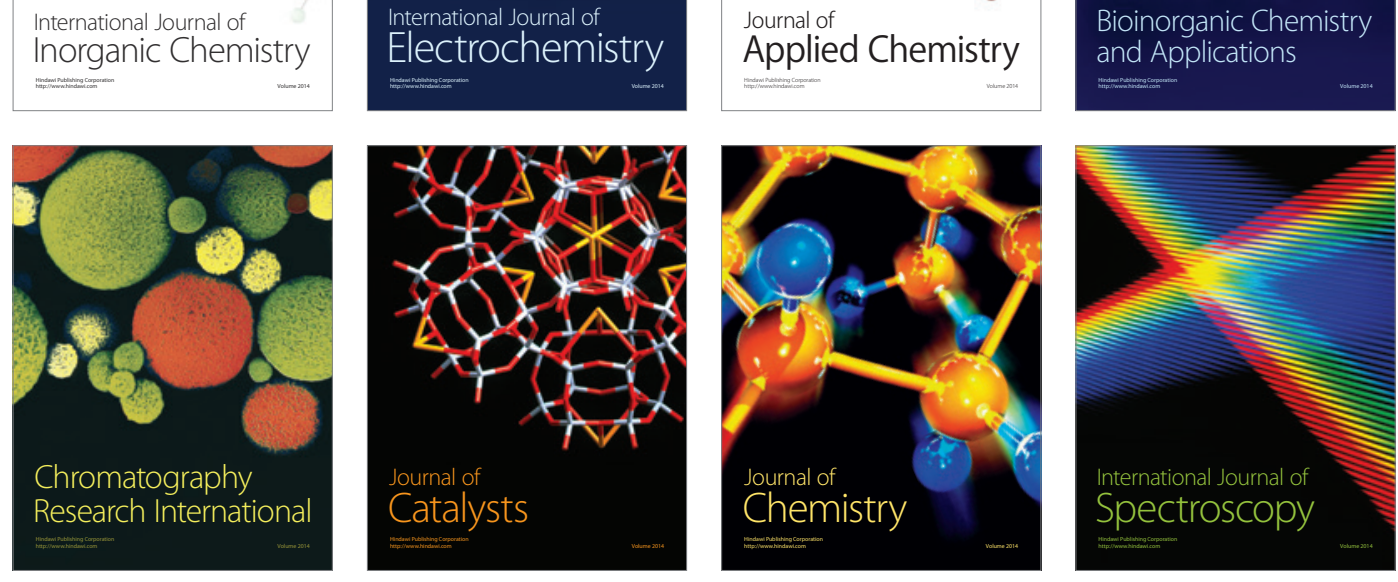